\title{
Improvements in 25 Years of Implantable Cardioverter Defibrillator Therapy
}

\author{
G. H. van Welsenes • C. J. W. Borleffs • J. B. van Rees • \\ J. Z. Atary • J. Thijssen • E. E. van der Wall • \\ M. J. Schalij
}

Published online: 22 December 2010

(C) The Author(s) 2010. This article is published with open access at Springerlink.com

\begin{abstract}
In 1980, Dr. Michel Mirowski and his team inserted the first implantable cardioverter defibrillator (ICD) in a patient. Initially, ICD therapy was not widely accepted, and many physicians actually considered this therapy unethical. Large secondary and primary prevention trials, demonstrating a beneficial effect of ICD therapy in selected patients not only on arrhythmic death but also on all-cause mortality, stimulated a rapid growth in the number of implants and increased patient's and physician's acceptance. Improvements in size and weight, arrhythmia discrimination capabilities, battery technology, shock waveform and output, monitoring capabilities and defibrillator electrode technology eventually resulted in the current large number of yearly
\end{abstract}

The questions can be answered after the article has been published in print. You have to $\log$ in to: www.cvoi.nl.

G. H. van Welsenes · C. J. W. Borleffs • J. B. van Rees •

J. Z. Atary $\cdot$ J. Thijssen $\cdot$ E. E. van der Wall $\cdot$ M. J. Schalij $(\bowtie)$

Department of Cardiology, Leiden University Medical Center,

C5-P, P.O. Box 9600, 2300 RC, Leiden, the Netherlands

e-mail: m.j.schalij@lumc.nl

G. H. van Welsenes

e-mail: ghvanwelsenes@hotmail.com

C. J. W. Borleffs

e-mail: c.j.w.borleffs@lumc.nl

J. B. van Rees

e-mail: j.b.van_rees@lumc.nl

J. Z. Atary

e-mail: j.z.atary@lumc.nl

J. Thijssen

e-mail: j.thijssen@lumc.nl

E. E. van der Wall

e-mail: e.e.van_der_wall@lumc.nl implants. Today, almost 40 years after the conception of the ICD and 25 years after the first human implant, ICD therapy is the treatment of choice for patients at risk for lifethreatening arrhythmias either as secondary or primary prevention. Furthermore, with the more recent addition of resynchronisation therapy to standard ICD therapy, it became possible to treat selected patients with advanced symptoms of heart failure and to lower the risk of sudden death.

Keywords Implantable cardioverter defibrillator C Cardiac resynchronization therapy $\cdot$ Arrhythmia $\cdot$ Sudden death . Defibrillation

\section{Introduction}

Sudden cardiac death, mainly caused by ventricular arrhythmias (VA) in a population with coronary artery disease, is a major cause of mortality in the Western world. In the USA alone, the annual incidence of sudden cardiac death varies from 200,000 to 450,000 of which most fatal events occur outside the hospital [1]. Since the prevention of these events has always been difficult, Mirowski and coworkers developed the implantable cardioverter defibrillator (ICD), and in 1980, the first ICD was implanted in a human [2]. Initially, the ICD was thought to be a treatment of last resort for the prevention of sudden cardiac death. Soon it became clear that, if it were to be possible to identify patients at risk, it would be the treatment of choice for patients at high risk for life-threatening arrhythmias [3]. In 1984, 4 years after the first human implant, the first ICD was implanted in the Netherlands at the University Medical Center Utrecht.

The first ICDs were large $\left(8 \times 11.5 \mathrm{~cm}, 170 \mathrm{~cm}^{3}\right)$ and heavy $(280 \mathrm{~g})$. These devices required open chest surgery, 
and the device was implanted in the abdomen. Needless to say, these procedures were associated with a high rate of complications. Algorithms for the detection of potentially life-threatening VA were limited, and the occurrence of inappropriate device therapy was frequent. At that time, ICD therapy was not generally accepted and considered unethical and even inhuman by many. Despite the high failure rate of drug therapy, many physicians preferred treating their patients with antiarrhythmic drugs. Large secondary and primary prevention trials demonstrating the efficacy of ICD therapy were necessary to stimulate a wider use and to increase patient's acceptance.

Furthermore, first-generation devices were rather bulky, and many improvements in size and weight, arrhythmia discrimination, battery technology, shock waveform and output, monitoring capabilities, and defibrillator electrode technology were necessary to allow the current large-scale yearly implantations. However, the first human implants marked the start of a new way of treating patients at risk of dying suddenly. In other words, the era of ICD therapy had begun.

\section{Secondary Prevention Trials}

Initially, to be eligible for ICD treatment, patients had to survive at least one episode of life-threatening VA such as ventricular fibrillation (VF) or ventricular tachycardia (VT; secondary prevention). In the 1990s, three large trials proved the effectiveness of ICD therapy for the secondary prevention of arrhythmic death: the Antiarrhythmics Versus Implantable Defibrillator study (AVID) [4], the Canadian Implantable Defibrillator Study (CIDS) [5] and the Cardiac Arrest Study Hamburg (CASH; Table 1) [6]. The AVID trial enrolled patients who had survived a cardiac arrest or with documented sustained VAs. Patients were randomised to either amiodarone therapy or ICD treatment, and the primary endpoint was all-cause mortality. The results showed a reduction in all-cause mortality of $28 \%$ in the defibrillator group [4]. The CIDS trial had a similar design and showed a $20 \%$ reduction in mortality in the ICD group, compared with amiodarone treatment [5]. The CASH trial enrolled patients who survived an episode of cardiac arrest and randomised to either ICD therapy or antiarrhythmic drug therapy, showing a mortality reduction of $23 \%$ in the ICD group [6]. It should be noted that the AVID trial was the only trial to demonstrate significant survival benefit from ICD therapy, and according to critical reviews, this significance was even overestimated due to the threefold higher use of $\beta$-blockers in the ICD arm [7].

Nonsignificant results in the CIDS trial might be due to the early termination of the study after the data of the AVID were published. Even so, a similar trend to the AVID trial was observed. For the CASH trial, the smaller size of the study might explain the nonsignificance since the observed relative and absolute risk reductions were similar to the AVID and CIDS trials. A meta-analysis of these three trials provided more insight and demonstrated a significant $28 \%$ reduction in all-cause mortality in the ICD-treated group [8]. Eventually, the results of the AVID trial, the trend in the CIDS and the meta-analysis led to the acceptance of ICD therapy for the secondary prevention of sudden arrhythmic death [3].

\section{Primary Prevention Trials}

Since the survival rate of an episode of cardiac arrest is at best only $8 \%$, the impact of secondary prevention ICD therapy on population mortality will be low [9]. Therefore, focus shifted from secondary prevention to the identification of patients at risk of life-threatening VAs without a prior arrhythmic event. Large randomised trials tested the hypothesis that ICD treatment was beneficial in selected patients, prior to cardiac arrest or sustained VT (primary prevention; Table 2). The first primary prevention trial was the Multicenter Automatic Defibrillator Implantation Trial (MADIT), which enrolled patients with a prior myocardial infarction, left ventricular ejection fraction (LVEF) less than $35 \%$, documented nonsustained VT and inducible, nonsuppressible VT on electrophysiological study. Patients
Table 1 Clinical features and results of three major secondary prevention ICD trials

AVID Antiarrhythmics Versus Implantable Defibrillators study, CASH Cardiac Arrest Study Hamburg, CIDS Canadian Implantable Defibrillator Study, $I C D$ implantable cardioverter defibrillator, $V F$ ventricular fibrillation, $V T$ ventricular tachycardia, $V A$ ventricular arrhythmia

\begin{tabular}{|c|c|c|c|}
\hline Trials & AVID [4] & CIDS [5] & CASH [6] \\
\hline Sample size & 1016 & 659 & 288 \\
\hline Design & ICD vs antiarrhythmic drugs & ICD vs amiodarone & $\begin{array}{l}\text { ICD vs amiodarone } \\
\text { vs metoprolol }\end{array}$ \\
\hline Patients & $\begin{array}{l}\text { Resuscitated from near-fatal } \\
\text { VF or post-cardioversion } \\
\text { from sustained VT }\end{array}$ & $\begin{array}{l}\text { Resuscitated VF or VT } \\
\text { or with unmonitored } \\
\text { syncope }\end{array}$ & $\begin{array}{l}\text { Survivors of cardiac } \\
\text { arrest secondary to } \\
\text { documented VAs }\end{array}$ \\
\hline Follow-up (months) & 18 & 36 & 57 \\
\hline $\begin{array}{l}\text { Primary endpoint } \\
\text { Results }\end{array}$ & All-cause mortality & All-cause mortality & All-cause mortality \\
\hline Risk reduction with ICD & $28 \%(P=0.02)$ & $20 \%(P=0.14)$ & $23 \%(P=0.08)$ \\
\hline
\end{tabular}


Table 2 Clinical features and results of four primary prevention ICD trials

\begin{tabular}{|c|c|c|c|c|}
\hline Trials & MADIT [10] & MUSTT [11] & MADIT II [13] & SCD-HeFT [28] \\
\hline Sample size & 196 & 704 & 1232 & 2521 \\
\hline Design & $\begin{array}{l}\text { ICD vs antiarrhythmic } \\
\text { drugs as conventional } \\
\text { therapy }\end{array}$ & EP-guided therapy vs placebo & $\begin{array}{l}\text { ICD vs optimal } \\
\text { pharmacological } \\
\text { therapy }\end{array}$ & $\begin{array}{l}\text { ICD vs optimal pharmacological } \\
\text { therapy vs optimal pharmacological } \\
\text { therapy }+ \text { amiodarone }\end{array}$ \\
\hline Patients & $\begin{array}{l}\text { Previous MI, EF } \leq 0.35 \text {, } \\
\text { nsVT, positive findings } \\
\text { on EPS }\end{array}$ & $\begin{array}{l}\text { Coronary disease, } \mathrm{EF} \leq 0.40 \text {, } \\
\text { nonsustained VT, inducible } \\
\text { VT at EPS }\end{array}$ & Prior MI, EF $\leq 0.30$ & $\begin{array}{l}\text { Ischaemic and nonischaemic } \\
\text { cardiomyopathy, } \mathrm{EF} \leq 0.35\end{array}$ \\
\hline Follow-up (months) & 27 & 39 & 20 & 46 \\
\hline \multicolumn{5}{|l|}{ Results } \\
\hline Risk reduction with ICD & $54 \%(P=0.001)$ & $51 \%(P=0.001)$ & $31 \%(P=0.02)$ & $23 \%(P=0.007)$ \\
\hline
\end{tabular}

$E P$ electrophysiology, EPS electrophysiology study, ICD implantable cardioverter defibrillator, MADIT Multicenter Automatic Defibrillator Implantation Trial, $M I$ myocardial infarction, $E F$ ejection fraction, MUSTT Multicenter Unsustained Tachycardia Trial, $n s V T$ nonsustained ventricular tachycardia, SCD-HeFT Sudden Cardiac Death in Heart Failure Trial, VT ventricular tachycardia, $A A D$ antiarrhythmic drugs

were randomised to receive either amiodarone therapy or an ICD, and after the inclusion of 196 patients and with 27 months follow-up, the study demonstrated a $54 \%$ reduction in mortality in the ICD group [10]. Despite these findings, controversy about the study design remains. There was no registry of screened patients as in AVID, a high percentage discontinued taking amiodarone and the ICDtreated population showed a disproportionately higher use of $\beta$-blockers. The prevailing consensus was that more data were needed to support the MADIT findings. Therefore, the results of this study were not adopted in the guidelines until the results of the Multicenter Unsustained Tachycardia Trial (MUSTT) were published [11]. MUSTT enrolled patients with coronary artery disease, LVEF less than $40 \%$, documented nonsustained VT and inducible, nonsuppressible VT on electrophysiological study, and the survival rate was comparable with MADIT. Further analysis of the survival benefit in the MADIT showed that the highest benefit was observed in patients with an LVEF of less than $26 \%$ [12]. These and other observations from the MADIT trial resulted in a simplified design and a new study. The MADIT II trial randomised patients with a history of myocardial infarction and an LVEF less than $30 \%$ to either ICD therapy or no ICD without the requirement of additional electrophysiological testing and reported a $31 \%$ reduction for mortality in patients treated with an ICD [13]. A meta-analysis of ten primary prevention trials demonstrated a significant $25 \%$ reduction in all-cause mortality in the ICD-treated patients [14]. Consequently, these findings led to the inclusion of primary prevention ICD treatment in the current guidelines [3].

It is worth mentioning that due to the trial designs, left ventricular dysfunction has developed into the key determinant for the selection of prophylactic ICD implantation [15]. However, there are several limitations to this criterion. First of all, accurate measurement of LVEF appeared to be difficult resulting from different levels of experience and nonreproducibility [16]. Furthermore, community-wide registries have demonstrated that a significant group of nonsurvivors of sudden cardiac death had LVEF $>40 \%$ prior to the event and would therefore never be eligible for prophylactic ICD implantation [9]. Finally, only $35 \%$ of the patients eligible for primary prevention ICD treatment receive appropriate therapy during long-term follow-up [13]. Considering these limitations, more accurate risk markers for the prediction of sudden cardiac death are needed to improve patient selection criteria for prophylactic ICD implantation.

\section{Cardiac Resynchronisation Therapy Defibrillator}

Congestive heart failure (CHF) is associated with decreased haemodynamic function, exercise tolerance and quality of life due to poor left ventricular systolic or diastolic function. Furthermore, patients with CHF are at increased risk for sudden cardiac death. As already discussed, ICD treatment in CHF patients resulted in improved outcome and a reduction in all-cause mortality [17]. In a significant number of patients, left ventricular failure is associated with conduction disturbances causing mechanical dyssynchrony. Ventricular dyssynchrony further contributes to the already impaired left ventricular function. Electrical cardiac resynchronisation therapy (CRT) is a technique which corrects dyssynchrony caused by ventricular dilatation and electrical disturbance. In recent years, numerous randomised and observational studies have demonstrated that CRT may improve functional status, quality of life and may even lower mortality [18]. It was therefore a logical step to combine CRT with ICD therapy (CRT-D). The first CRT implantations in the Netherlands were performed in Utrecht by thoracic surgeon Dr. Bakker and her team. In 1994, Cazeau et al. were the first to report on the benefit from CRT in CHF patients. This study tested the safety and 
efficacy of multisite pacing in patients with heart failure. Significant improvements in exercise tolerance, New York Heart Association (NYHA) class and quality of life were noted. In 2003, the COMPANION trial was the first to randomise between optimal medical therapy, optimal medical therapy and CRT and optimal medical therapy and CRT-D. CRT-D reduced mortality by $36 \%$ in comparison with standard therapy, whereas CRT alone resulted in a $20 \%$ reduction in mortality [17]. Other studies (CARE-HF) demonstrated that CRT alone had the same effect on mortality as CRT-D in the COMPANION trial. Recently, the Multicenter Automatic Defibrillator Implantation Trial-Cardiac Resynchronization Therapy (MADITCRT) enrolled patients with NYHA class I or II, QRS duration $\geq 130 \mathrm{~ms}$ and LVEF $\leq 30 \%$. Patients were randomised to ICD therapy alone or to ICD therapy with CRT. The primary endpoint was a composite of allcause mortality and nonfatal heart failure, and during follow-up, $17 \%$ in the CRT-D group and $25 \%$ in the ICD group reached the primary endpoint. It was concluded that the incidence of all-cause mortality and nonfatal heart failure was significantly reduced when CRT was added to ICD therapy [18].

\section{The Device}

The first ICD was large and heavy, could not be programmed, used epicardial patch electrodes and required a thoracotomy for the implantation of the epicardial lead system. ICD implantation procedures were major surgical interventions, associated with significant morbidity and mortality. Fortunately, since then, many improvements have been made. Current devices are relatively small, can be implanted subcutaneously in the majority of cases and are connected to an endocardial lead system (Figs. 1 and 2).

\section{Components and Function}

An ICD contains a battery, a capacitor to store and deliver charges, a microprocessor and integrated circuits for electrogram sensing, data capture, storage and control of therapy delivery, a header to connect the endocardial leads used for sensing, pacing and defibrillation (Fig. 3). All these components together are called a pulse generator and are encased in a titanium can. The collaboration of these components results in the essential features of ICD function, including sensing, detecting and classification of tachyarrhythmias, delivering therapy (ventricular defibrillation or antitachycardia pacing (ATP)), monitoring heart rhythm after therapy and storage of episodes. In this process, the sensing function determines the depolarisation sequences of each atrial and ventricular depolarisation and the detecting function classifies the rhythm by an algorithm and determines if therapy should be delivered [19].

The device implanted in the 1980 s, called the automatic implantable cardiac defibrillator, was designed only to recognise and terminate VF by delivering a high-energy shock [2]. These early devices could not detect unstable VTs which could degenerate into VF, and because these devices lacked programmability, separate pacemakers were required to allow backup bradycardia pacing, leading to dangerous interactions [19]. Development of secondgeneration devices facilitated bradycardia pacing capabilities and were (minimally) programmable. Especially the bradycardia pacing capability was important as it ended the need for separate pacemakers. Additionally, these devices had a limited telemetry function used to test battery strength
Fig. 1 Example of abdominal implanted ICD system in a 15-year-old female. ICD implantable cardioverter defibrillator

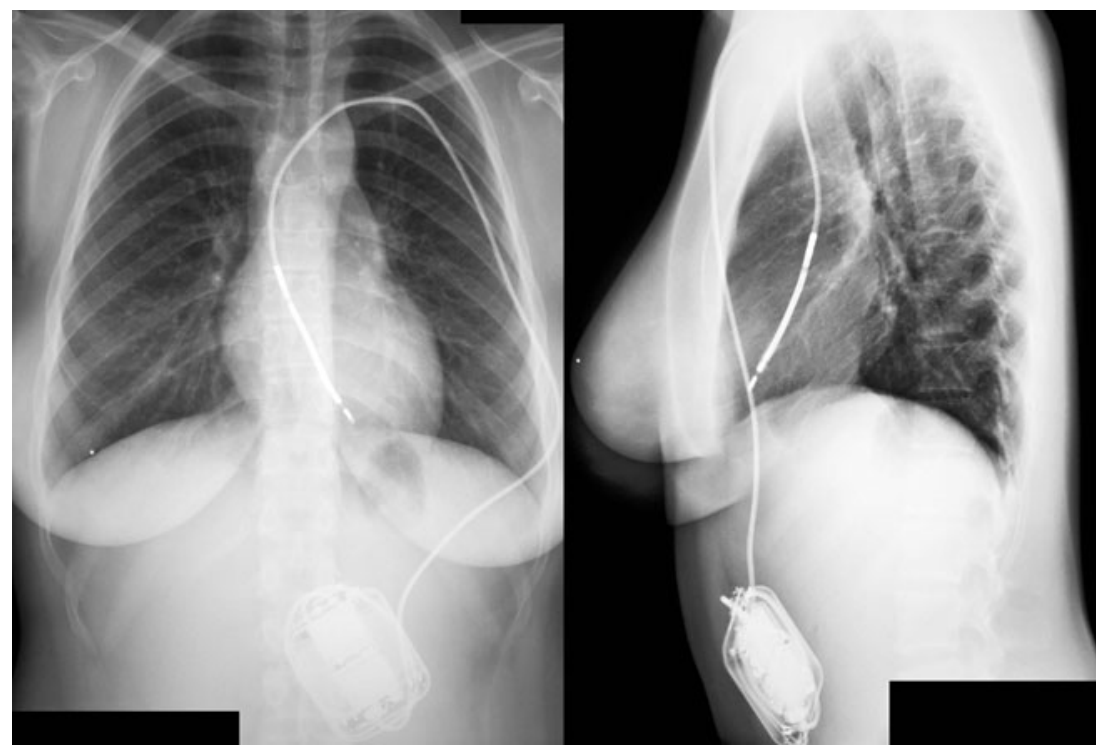


Fig. 2 Example of pectoral implanted CRT-D system in a 42-year-old male. CRT-D cardiac resynchronisation therapy—defibrillator

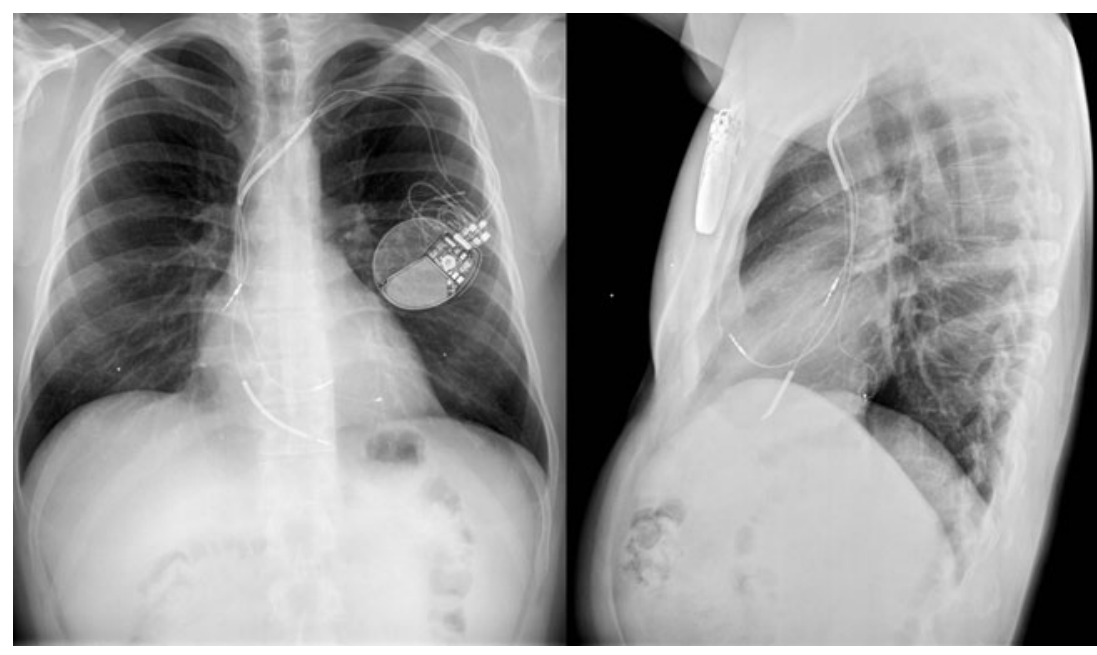

and simply note the number of delivered shocks. For this telemetry function, an external monitoring device was needed. In the next decade, many improvements were made, and in the early 1990s, the first third-generation devices were introduced. In these devices, ATP was introduced as well as low-energy shocks for terminating VTs, extensive programmability and telemetry functions [20]. Current devices can be programmed into three or even four different cycle lengthrelated zones, and different schemes of ATP, shock or a combination of both can be programmed.

\section{Battery and Capacitor}

First-generation devices contained cylindrical aluminium electrolytic capacitors and silver vanadium pentoxide batteries for rapid charge time and the delivery of high-voltage shocks [21]. Nowadays, lithium-silver vanadium manganese oxide batteries are used, which resulted in an increase of the service life of an ICD. Some models use two batteries connected in series to minimise charge time, thereby improving patient safety. However, this reduction in charge time is

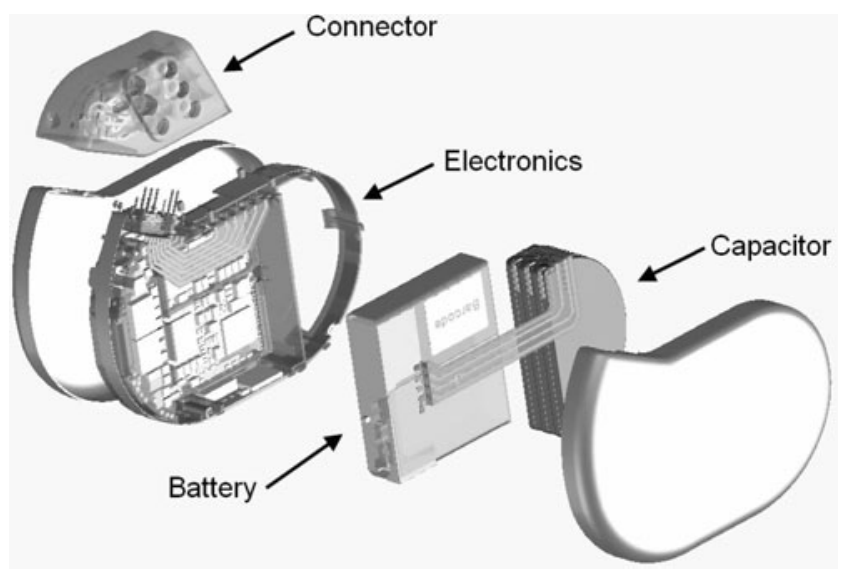

Fig. 3 Exploded view of an ICD. ICD implantable cardioverter defibrillator. Image provided by Biotronik accompanied with an undesirable increase in ICD size, since the sizes of the battery and capacitor are the major determinants of the size of the ICD. Therefore, it is important to develop capacitors which require a minimum of stored energy but still deliver enough energy for defibrillation without affecting the ICD service life [22].

\section{Leads}

The large first-generation devices were implanted abdominally and needed a thoracotomy to place the lead system. The lead system used contained a spring patch and apical cup. The second-generation devices eliminated thoracotomy by the introduction of transvenous leads in 1988. With the introduction of these transvenous leads, the implantation procedure was transformed from open chest surgery to a procedure performed in the electrophysiology laboratory [23]. Further research evaluated the safety and efficacy of transvenous ICD implantation performed entirely by electrophysiologists and demonstrated a high success rate, low complication occurrence and short implantation time and made subcutaneous ICD implantation in the electrophysiology laboratory the method of choice.

Besides improvements in the implantation procedures, improvements were made in the construction of the leads. Two different kinds of leads are implanted, the coaxial lead design (Fig. 4, left) in the first- and second-generation devices and the multilumen lead design (Fig. 4, right) in third-generation devices [24]. The coaxial lead has a layered design composed of a tip conductor, ring conductor and defibrillation conductor and an insulation layer between each conductor. The multilumen lead construction is based on parallel running conductors through a single insulating body. Tip and ring conductors are used for pacing and sensing, a defibrillation conductor for the coil located in the right ventricle and a defibrillation conductor for the coil located in the superior vena cava. The insulating body contains extra 


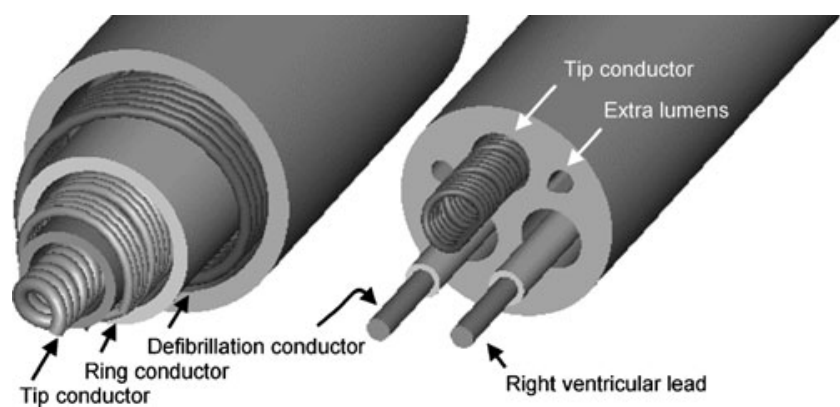

Fig. 4 Cross section of coaxial lead construction of a single coil defibrillation lead with true bipolar sensing and pacing (left) and cross section of multilumen lead construction (right). Image provided by Medtronic

lumens to increase the lead's resistance to compression forces. The major advantage of multilumen over coaxial leads is the fact that more conductors will fit into overall smaller leads [24].

Despite improvements in the construction of leads, lead failure occurs frequently. Due to the different design and materials which are used, longevity of current implanted leads may differ significantly [25]. Borleffs et al. evaluated the survival and failure rate in a large number of defibrillation leads implanted over a 16-year period [26]. The implanted leads were produced by different manufacturers, and different lead diameters were used. Borleffs et al. demonstrated major differences in failure rates among different groups and showed an overall 10-year lead survival rate of $73 \%$. Based on these findings, it is important to carefully select the type of leads which are used for each patient and to optimise future lead performance [26].

\section{Longevity}

Since the first implantation in 1980, worldwide implantation rates have increased, and therefore, the number of ICD replacements is expected to increase dramatically. Most of the replacements are due to end of service life (battery depletion), and every implantation or replacement brings a substantial risk of complications. The major determinant of ICD longevity is the capacitor and therefore the ICD size. Hauser compared the cumulative survival of ICD patients with ICD longevity. The probability of a patient living 4,5 and 6 years after implantation was $79 \%, 75 \%$ and $68 \%$, respectively. Furthermore, the study suggested that if an ICD had ten service years, the majority of patients would not need a replacement [27]. A feasible solution is to produce larger pulse generators with batteries with longer service life. However, this will impact patients' acceptance and possibly cause more pocket-related problems due to the larger volume of the devices. Furthermore, because of the fast development of new ICD features, it will sometimes be questionable if it is really desirable to implant devices with a projected longevity of ten or more years. Replacement of the currently used lithium-silver vanadium oxide batteries with large-capacity batteries can increase service life by 2.3 years [27]. These large-capacity batteries increase the size and weight of the device and are in conflict with downsizing the device as the market forces.

\section{Algorithms and Rhythm Discrimination}

First-generation devices were designed to detect VF only by waveform analyses. The standard waveform analysis used to identify cardiac rhythm was the rate of $\mathrm{R}$ waves. Due to the limitations of waveform analyses only, inappropriate therapy occurred frequently, since episodes of supraventricular tachycardia with fast ventricular response could be classified as VT or VF and cause inappropriate shocks. The first detection criterion in all current devices is the signal rate recorded by the right ventricular lead. In order to confirm a ventricular tachyarrhythmia, a specified number of sensed events must occur at a higher rate than the cutoff rate.

To improve specificity in discriminating between VT or supraventricular tachycardia, various algorithms have been developed. As mentioned previously, current ICDs can be programmed into three different cycle length-related zones and the discriminative detection algorithms can be programmed in the two lowest zones. The highest programmable zone is meant for detection of fast VT or VF without any further discrimination to avoid unnecessary therapy delivery delay. Single chamber devices use algorithms to discriminate rhythms, comparing the morphology of the arrhythmia with the morphology of baseline sinus rhythm, the rate of onset of arrhythmia and rhythm regularity. Dual-chamber devices can use additional information retrieved from the atrial lead for discriminating between rhythms.

All currently available algorithms have some known limitations such as false-positive and false-negative therapy delivery decisions, but by combining some of these algorithms, the amount of inappropriate inhibition or therapy delivery can be further reduced. The complexity and combination of algorithms which can be used depends on power requirements of the ICD. Since downsizing the ICD is an important goal, larger batteries which can provide the power requirements for complex algorithms are not used. These constraints reduce the use of more complex algorithms, and despite advances in algorithms, inappropriate therapy still occurs.

\section{Conclusions}

Since the introduction of ICD therapy 25 years ago, many device improvements have been made in size and weight reduction, arrhythmia discrimination, battery technologies, shock waveforms, monitoring capabilities and new defibrilla- 
tor electrodes, which have led to wider use and greater patient acceptance. In the beginning of ICD therapy, patients had to survive a life-threatening VA to be eligible for ICD treatment, but due to minimal survival rates, focus shifted to the identification of patients at high risk. Over the years, many secondary and primary trials have been executed, and the findings led to evolving guidelines for ICD implantation. The ICD is currently regarded as everyday therapy for large patient groups worldwide. Although the beneficial effects of ICD therapy are clearly proven in a selected population, ongoing advances in ICD technology and patient selection are necessary to improve device longevity, lead survival and to minimise the occurrence of adverse events.

Open Access This article is distributed under the terms of the Creative Commons Attribution Noncommercial License which permits any noncommercial use, distribution, and reproduction in any medium, provided the original author(s) and source are credited.

\section{References}

1. Zipes DP, Camm AJ, Borggrefe M, Buxton AE, Chaitman B, Fromer M, et al. ACC/AHA/ESC 2006 guidelines for management of patients with ventricular arrhythmias and the prevention of sudden cardiac death: a report of the American College of Cardiology/American Heart Association Task Force and the European Society of Cardiology Committee for Practice Guidelines (writing committee to develop guidelines for management of patients with ventricular arrhythmias and the prevention of sudden cardiac death). J Am Coll Cardiol. 2006;48:e247-346.

2. Mirowski M, Reid PR, Mower MM, Watkins L, Gott VL, Schauble JF, et al. Termination of malignant ventricular arrhythmias with an implanted automatic defibrillator in human beings. $\mathrm{N}$ Engl J Med. 1980;303:322-4.

3. Epstein AE, Dimarco JP, Ellenbogen KA, Estes III NA, Freedman RA, Gettes LS, et al. ACC/AHA/HRS 2008 guidelines for devicebased therapy of cardiac rhythm abnormalities: a report of the American College of Cardiology/American Heart Association Task Force on Practice Guidelines (writing committee to revise the ACC/AHA/NASPE 2002 guideline update for implantation of cardiac pacemakers and antiarrhythmia devices) developed in collaboration with the American Association for Thoracic Surgery and Society of Thoracic Surgeons. J Am Coll Cardiol. 2008;51:e1-62.

4. A comparison of antiarrhythmic-drug therapy with implantable defibrillators in patients resuscitated from near-fatal ventricular arrhythmias. The Antiarrhythmics versus Implantable Defibrillators (AVID) Investigators. N Engl J Med. 1997;337:1576-83.

5. Connolly SJ, Gent M, Roberts RS, Dorian P, Roy D, Sheldon RS, et al. Canadian implantable defibrillator study (CIDS): a randomized trial of the implantable cardioverter defibrillator against amiodarone. Circulation. 2000;101:1297-302.

6. Kuck KH, Cappato R, Siebels J, Ruppel R. Randomized comparison of antiarrhythmic drug therapy with implantable defibrillators in patients resuscitated from cardiac arrest: the Cardiac Arrest Study Hamburg (CASH). Circulation. 2000;102:748-54.

7. Tung R, Zimetbaum P, Josephson ME. A critical appraisal of implantable cardioverter-defibrillator therapy for the prevention of sudden cardiac death. J Am Coll Cardiol. 2008;52:1111-21.

8. Connolly SJ, Hallstrom AP, Cappato R, Schron EB, Kuck KH, Zipes DP, et al. Meta-analysis of the implantable cardioverter defibrillator secondary prevention trials. AVID, CASH and CIDS studies. Antiarrhythmics vs Implantable Defibrillator study. Cardiac Arrest Study Hamburg. Canadian Implantable Defibrillator Study. Eur Heart J. 2000;21:2071-8.

9. de Vreede-Swagemakers JJ, Gorgels AP, Dubois-Arbouw WI, van Ree JW, Daemen MJ, Houben LG, et al. Out-of-hospital cardiac arrest in the 1990's: a population-based study in the Maastricht area on incidence, characteristics and survival. J Am Coll Cardiol. 1997;30:1500-5.

10. Moss AJ, Hall WJ, Cannom DS, Daubert JP, Higgins SL, Klein H, et al. Improved survival with an implanted defibrillator in patients with coronary disease at high risk for ventricular arrhythmia. Multicenter Automatic Defibrillator Implantation Trial Investigators. N Engl J Med. 1996;335:1933-40.

11. Buxton AE, Lee KL, Fisher JD, Josephson ME, Prystowsky EN, Hafley G. A randomized study of the prevention of sudden death in patients with coronary artery disease. Multicenter Unsustained Tachycardia Trial Investigators. N Engl J Med. 1999;341:1882-90.

12. Moss AJ, Fadl Y, Zareba W, Cannom DS, Hall WJ. Survival benefit with an implanted defibrillator in relation to mortality risk in chronic coronary heart disease. Am J Cardiol. 2001;88:516-20.

13. Moss AJ, Zareba W, Hall WJ, Klein H, Wilber DJ, Cannom DS, et al. Prophylactic implantation of a defibrillator in patients with myocardial infarction and reduced ejection fraction. $\mathrm{N}$ Engl $\mathrm{J}$ Med. 2002;346:877-83.

14. Nanthakumar K, Epstein AE, Kay GN, Plumb VJ, Lee DS. Prophylactic implantable cardioverter-defibrillator therapy in patients with left ventricular systolic dysfunction: a pooled analysis of 10 primary prevention trials. J Am Coll Cardiol. 2004;44:2166-72.

15. Wilde AA, Simmers TA. Primary prevention with ICDs, are we on the right track? Neth Heart J. 2009;17:92-4.

16. Bracke FA, Dekker LR, van der Voort PH, Meijer A. Primary prevention with the ICD in clinical practice: not as straightforward as the guidelines suggest? Neth Heart J. 2009;17:107-10.

17. Bristow MR, Saxon LA, Boehmer J, Krueger S, Kass DA, De MT, et al. Cardiac-resynchronization therapy with or without an implantable defibrillator in advanced chronic heart failure. N Engl J Med. 2004;350:2140-50.

18. Moss AJ, Hall WJ, Cannom DS, Klein H, Brown MW, Daubert JP, et al. Cardiac-resynchronization therapy for the prevention of heart-failure events. N Engl J Med. 2009;361:1329-38.

19. Swerdlow CD, Friedman PA. Advanced ICD troubleshooting: part I. Pacing Clin Electrophysiol. 2005;28:1322-46.

20. Bardy GH, Troutman C, Poole JE, Kudenchuk PJ, Dolack GL, Johnson G, et al. Clinical experience with a tiered-therapy, multiprogrammable antiarrhythmia device. Circulation. 1992;85:1689-98.

21. Holley LK. Development of device therapy for ventricular arrhythmias. Heart Lung Circ. 2007;16:162-9.

22. Kroll MW, Swerdlow CD. Optimizing defibrillation waveform for ICDs. J Interv Card Electrophysiol. 2007;18:247-63.

23. Cannom DS, Prystowsky EN. The evolution of the implantable cardioverter defibrillator. Pacing Clin Electrophysiol. 2004;27:419-31.

24. Gradaus R, Breithardt G, Bocker D. ICD leads: design and chronic dysfunctions. Pacing Clin Electrophysiol. 2003;26:649-57.

25. van Dessel PF. The Sprint Fidelis lead fracture story: time to come to our senses? Neth Heart J. 2010;18:4-6.

26. Borleffs CJ, van Erven L, van Bommel RJ, van der Velde ET, van der Wall EE, Bax JJ, et al. Risk of failure of transvenous implantable cardioverter-defibrillator leads. Circ Arrhythm Electrophysiol. 2009;2:411-6.

27. Hauser RG. The growing mismatch between patient longevity and the service life of implantable cardioverter-defibrillators. J Am Coll Cardiol. 2005;45:2022-5.

28. Bardy GH, Lee KL, Mark DB, Poole JE, Packer DL, Boineau R, et al. Amiodarone or an implantable cardioverter-defibrillator for congestive heart failure. N Engl J Med. 2005;352:225-37. 